\title{
Determination of Copper in Different Ethanolic Matrices Using a Chloropropyl Silica Gel Modified with a Nanostructured Cubic Octa(3-aminopropyl)octasilsesquioxane
}

\author{
Devaney Ribeiro Do Carmo, ${ }^{1}$ Urquisa De Oliveira Bicalho, ${ }^{1}$ Tayla Fernanda a Silveira, \\ Newton Luiz Dias Filho, ${ }^{1}$ and Leonardo Lataro Paim ${ }^{2}$ \\ ${ }^{1}$ Faculdade de Engenharia de Ilha Solteira, UNESP_Univ Estadual Paulista, Departamento de Física e Química, Avenida Brasil \\ Centro 56, 15385-000 Ilha Solteira, SP, Brazil \\ ${ }^{2}$ Instituto de Química de Araraquara, UNESP_Univ Estadual Paulista, Rua Francisco Degni 55, CEP 14800-900 Araraquara, SP, \\ Brazil
}

Correspondence should be addressed to Devaney Ribeiro Do Carmo; docarmo@dfq.feis.unesp.br

Received 16 March 2013; Revised 24 April 2013; Accepted 12 May 2013

Academic Editor: Patricia Valentao

Copyright (C) 2013 Devaney Ribeiro Do Carmo et al. This is an open access article distributed under the Creative Commons Attribution License, which permits unrestricted use, distribution, and reproduction in any medium, provided the original work is properly cited.

The chloropropyl silica gel was modified with octa(3-aminopropyl)octasilsesquioxane and characterized by Fourier transform infrared (FTIR) spectroscopy, nuclear magnetic resonance (NMR), spectroscopies, and surface and area porosity. The specific sorption capacity of metallic ions $\left(\mathrm{Cu}^{2+}\right.$ and $\left.\mathrm{Ni}^{2+}\right)$ increases in the following solvent order: water $<$ ethanol $42 \%<$ ethanol $<\mathrm{ketone}$. The high values of the constant $(\mathrm{K})$ in the order of $10^{3} \mathrm{~L} \mathrm{~mol}^{-1}$ suggested the high adsorbent capacity of the modified silica (SGAPC) for $\mathrm{Cu}^{2+}$ and $\mathrm{Ni}^{2+}$. SGAPC was applied to a separation column and shows recoveries of around $100 \%$ of copper in samples of sugar cane spirit, vodka, ginger brandy, and ethanol fuel.

\section{Introduction}

Silsesquioxane $[1,2]$ usually refers to all structures which have the empirical formula $\left(\mathrm{RSiO}_{1.5}\right)_{n}$, where $\mathrm{R}$ can be a hydrogen or any organic group such as alkyl, methyl, aryl, vinyl, phenyl, or any derivative of these organic groups. Each silicon atom is connected to an average of 1.5 oxygen atoms and one R group (hydrocarbon). When $n=4,6,8,10(n \geq 4)$, the resulting compounds are called polyhedral oligomeric silsesquioxanes (POSS) $[3,4]$, and if $\mathrm{n}$ is any other number it is simply called polysilsesquioxanes. POSS have cubic silica cores with a diameter of $0.53 \mathrm{~nm}$ and a spherical radius of 1$3 \mathrm{~nm}$ including peripheral organic units.

In recent years, the remarkable increase in the number of patent applications for silsesquioxane materials is due to the structural similarities and electronic properties exhibited by the silanol groups produced by silica. The ability of silsesquioxane to mimic the reactivity of silanol groups on the silica surface is responsible for the significant progress in understanding the chemistry of silsesquioxanes $[1,5,6]$.

Over the last decade, there have been studies published on the interaction of elements in group 1A and transition metals with the silanol groups of incompletely condensed cage structure $[3,7]$. These nanostructures are capable of mimicking the main features of the heterogeneous inorganic silica modified with transition metals. The key features include electrodonor sites [8], interactions with adjacent oxygen donors [9] that contribute to the stability of immobilized clusters on the surface and defined orientation of the hydroxyl groups on the surface [10], which determine the selectivity by which the compound reacts with the surface.

There are multiple silsesquioxane applications, and when they are used as precursors in the formation of organicinorganic hybrid materials [11] there are even more potential applications. The most common [6] are those related to technological importance, such as additive agents [12] (crosslinking, thermal and viscosity modifiers), polymers 
[13] (medical supplies, advanced plastics, resins, elastomers), electroactive films $[14,15]$, and precursors for silica interface $[6,8]$.

In this work, the objective is to immobilize the Octa(3aminopropyl)octasilsesquioxane (APC) in 3 chloropropyl silica gel (SG) and apply the modified silica (SGAPC) to the sorption of metals $\left(\mathrm{Cu}^{2+}\right.$ and $\left.\mathrm{Ni}^{2+}\right)$ in aqueous and/or organic solution, and thereafter test this in the removal of $\mathrm{Cu}^{2+}$ species in real samples of sugar cane spirit, vodka, ginger brandy, and fuel alcohol. Similar to a ligand, APCs have a large number of $-\mathrm{NH}_{2}$ functional groups, with which they can attach to the 3-chloropropyl silica gel surface. The chelating capacity of nonattached $\mathrm{NH}_{2}$ on the SG surface can be used to adsorb metal ions in the environmental and biological samples in organic or aqueous media. Copper is a metal regarded as essential for human health, which is present in all fluids and many tissues. This element, along with amino acids, fatty acids, and vitamins, is necessary for metabolic processes. The sugar cane spirit or "cachaça" is a beverage obtained by the distillation of fermented sugar cane mash and must follow important quality standards for human consumption. Originated during the distillation process, copper has its maximum limit set at $5 \mathrm{mg} \mathrm{L}^{-1}$, according to the Ministry of Agriculture, Livestock and Supply [16]. Excess copper can be toxic because of the affinity of metal with the SH groups of many proteins and enzymes, which is associated with diseases such as epilepsy, rheumatoid arthritis, melanoma, and the loss of taste $[17,18]$.

\section{Experimental}

2.1. Apparatus. Fourier transform infrared (FTIR) spectra were recorded on a Nicolet 5DXB FTIR 300 spectrometer (Nicolet Instruments, Madison, WI). The pellets were prepared with $150 \mathrm{mg}$ of $\mathrm{KBr}$ and $1 \%$ (w/w) of solid samples, and each sample was scanned 64 times at $\mathrm{a} \pm 4 \mathrm{~cm}^{-1}$ resolution.

All solid-state NMR analyses of ${ }^{29} \mathrm{Si}(59.5 \mathrm{MHz})$ and ${ }^{13} \mathrm{C}$ (75.4 MHz) were recorded on a Varian INOVA 300 spectrometer with a silicon nitride rotor. The ${ }^{29} \mathrm{Si}$ experiments were performed using an acquisition time of $0.005 \mathrm{~s}$, pulse $84.4^{\circ}$, with 156 replications, a rotation rate of 2300, and an average time of $2 \mathrm{~h}$. For ${ }^{13} \mathrm{C}$, the acquisition time was of $0.005 \mathrm{~s}$, pulse $28.4^{\circ}$, with 13300 replications, a rotation rate of 6000 , and an average time of $15 \mathrm{~h}$.

The physical characteristics of silica, such as surface area, porosity, and pore distribution, were determined by $\mathrm{N}_{2}$ sorption, Brunauer Emmett Teller (BET) (particle surface area measurements) using a Micromeritics ASAP 2010 physicochemical sorption apparatus.

2.2. Reagents and Solutions. Chloropropyl-silica (ClPS) was purchased from Sigma-Aldrich (Merck) and was used as received. All other chemicals used in the electrochemical experiments were of analytical-reagent grade. Milli-Q water was used to prepare all solutions.

\subsection{Preparation Method of Materials}

2.3.1. Preparation of Octa(3-aminopropyl)octasilsesquioxane (APC). Octa(3-aminopropyl)octasilsesquioxane $\left(\left[\mathrm{H}_{2} \mathrm{~N}\left(\mathrm{CH}_{2}\right)_{3}\right]_{8} \mathrm{Si}_{8} \mathrm{O}_{12}\right)$ was prepared according to the procedure described in the literature [19] with some modifications. The preparation of octa (3-aminopropyl)octasilsesquioxane used a two-step process.

Step 1. Concentrated $\mathrm{HCl}(200 \mathrm{~mL})$ was carefully added, under stirring, to a solution. A $150 \mathrm{~mL}$ syringe containing $\gamma$-aminopropyltriethoxysilane $\left(\mathrm{H}_{2} \mathrm{NCH}_{2} \mathrm{CH}_{2} \mathrm{CH}_{2} \mathrm{Si}(\mathrm{OEt})_{3}\right)$ was slowly added to methanol anhydrous $(3.6 \mathrm{~L})$ in a $4.0 \mathrm{~L}$ three-neck round bottom flask. The capped flask was left to sit for 6 weeks at $30^{\circ} \mathrm{C}$. The product from the reaction mixture usually begins to crystallize after 3-4 weeks. A solution of octahydrochloride salt of around $31 \%$ was obtained, washed with cold methanol, and then dried at room temperature. The resulting product, the octahydrochloride salt, was designated (1).

Step 2. Neutralization of (1). Amberlite IRA-400 (Cl) ionexchange resin (37 g) was prepared by successive washing with water $(4 \times 200 \mathrm{~mL}), 1 \mathrm{~mol} \mathrm{~L}^{-1} \mathrm{NaOH}(3 \times 200 \mathrm{~mL})$, water $(6 \times 200 \mathrm{~mL})$. The resin was suspended in an eluent and chilled $\left(-10^{\circ} \mathrm{C} ; 2 \mathrm{~h}\right.$.) before use. Half of the resin beads were loaded onto a column ( $3.5 \mathrm{~cm}$ outer diameter); the other half was used to dissolve a suspension of (1). The elution passing through the column produced a stock solution that tested negative for chloride. To avoid decomposition, the amine should be prepared immediately before use and stored in methanol solutions at $-35^{\circ} \mathrm{C}$. The purity and identity of these compounds were confirmed by conventional microanalysis analytical methods $(\mathrm{C}, \mathrm{N}, \mathrm{H})$ and infrared (FTIR). The resulting composite was designated as APC.

2.3.2. Grafting APC on the ClPS Surface. About $5.0 \mathrm{~g}$ CIPS was added to $1.0 \mathrm{~g}$ of APC dissolved in $25 \mathrm{~mL}$ of methanol. The suspension was maintained at a reflux system for $48 \mathrm{~h}$ under constant agitation. The solid formed was separated, packed in filter paper, and then washed with methanol in a Soxhlet system for $48 \mathrm{~h}$. The material was then dried at $80^{\circ} \mathrm{C}$ in a vacuum oven and named SGAPC. Figure 1 shows a scheme for the preparation of SGAPC.

2.4. Adsorption Isotherms of Copper and Nickel. The adsorption isotherms of $\mathrm{CuCl}_{2}$ and $\mathrm{NiCl}_{2}$ from ketone, ethanol, ethanol $42 \%$, and aqueous solutions on the SGAPC surface were determined using the batchwise technique. For each isotherm, a series of samples containing $0.060 \mathrm{~g}$ of the adsorbent in $50.0 \mathrm{~mL}$ solvent with varying concentrations of copper chloride were mechanically shaken for $40 \mathrm{~min}$, at a constant temperature of $25 \pm 1^{\circ} \mathrm{C}$. The concentration of the metal ions in solution, in equilibrium with the solid phase, was determined by Flame atomic absorption spectrometry (FAAS) using a Perkin Elmer Analyst 700 spectrophotometer. For the calibration, synthetic standard solutions containing $1.0 \mathrm{~mol} \mathrm{~L}^{-1} \mathrm{HCl}$ were used for comparison with the samples. 

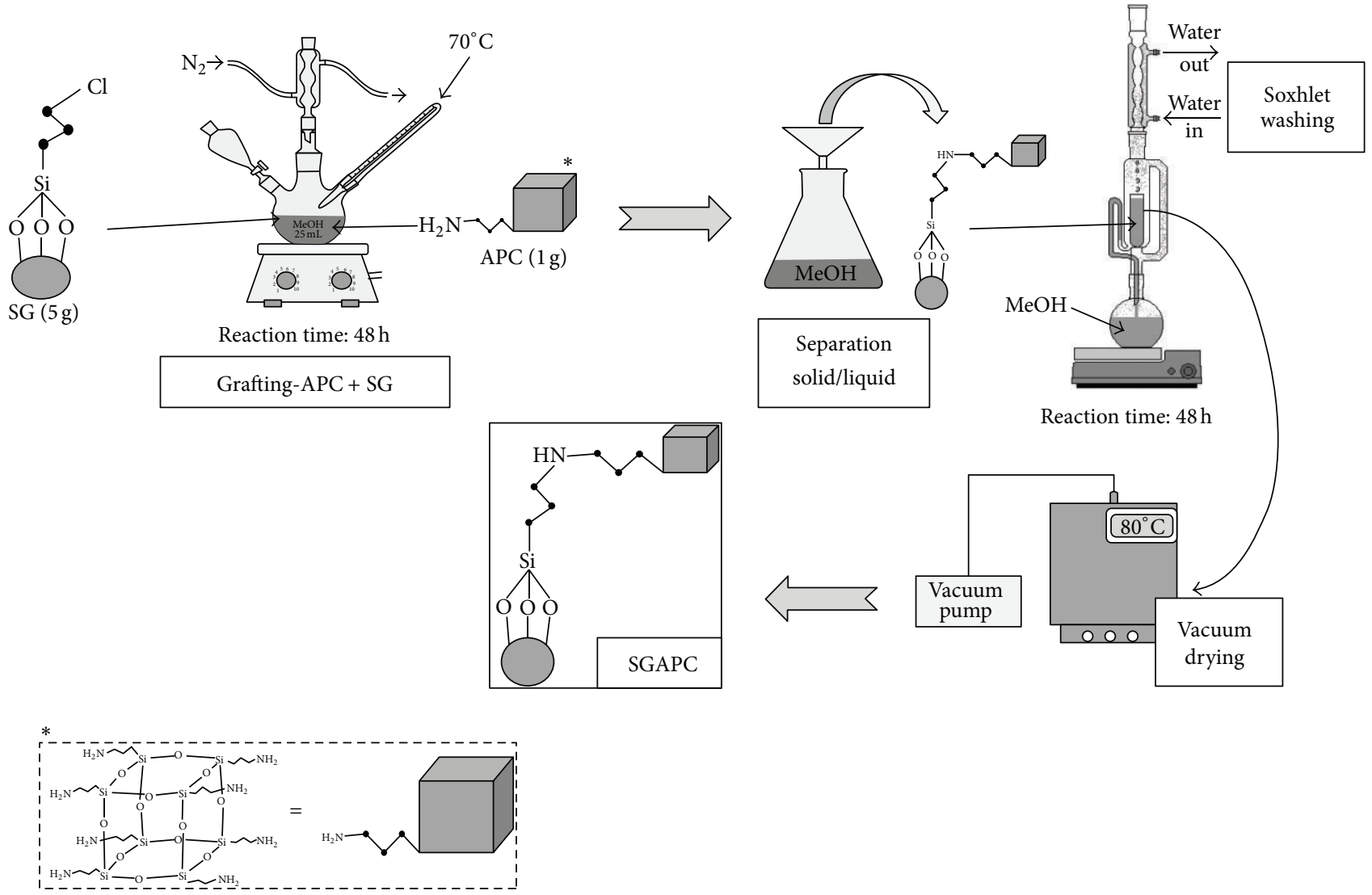

FIGURE 1: Schematic representation of SGAPC preparation.

2.5. SGAPC Application for Copper Determination in Beverages and Ethanol Fuel. The SGAPC application for the preconcentration and recovery of copper was carried out using a glass tube $\left(15 \mathrm{~cm}^{-1}\right.$ in length and $0.6 \mathrm{~cm}$ inner diameter) equipped with a double way valve packed with SGAPC. About $100 \mathrm{~mL}$ of samples were percolated through the column packed with $2 \mathrm{~g}$ of SGAPC and rated up by a peristaltic pump. Adsorbed metal ions were eluted with $5 \mathrm{~mL}$ of $1.0 \mathrm{~mol} \mathrm{~L}^{-1} \mathrm{HCl}$ solution, and the copper ions were analyzed by FAAS, using a $324.8 \mathrm{~nm}$ wavelength with a slit aperture of $0.7 \mathrm{~cm}$, acetylene gas and air flow of $2.0 \mathrm{~L} \mathrm{~min}^{-1}$ and $17.0 \mathrm{~L} \mathrm{~min}^{-1}$, respectively; the calibration curve was at a concentration range of 1$7 \mathrm{mg} \mathrm{L}^{-1}$, and the correlation coefficient was 0.9999 . The column was regenerated by passing $50 \mathrm{~mL}$ of $0.5 \mathrm{~mol} \mathrm{~L}^{-1} \mathrm{HCl}$ and then a solution of $\mathrm{KOH} 0.5 \mathrm{~mol} \mathrm{~L}^{-1}(50 \mathrm{~mL})$ and finally with deionized water.

2.5.1. Real Samples. After the recovery study, the column was percolated with real samples of sugar cane spirit ("cachaça"), vodka (38\%), ginger brandy, and ethanol fuel. The elution of the adsorbed species in the column was performed with $3.0 \mathrm{~mL} \mathrm{HCl} 1.0 \mathrm{~mol} \mathrm{~L}^{-1}$, and it was diluted to $5.0 \mathrm{~mL}$ with deionized water.

\section{Results and Discussion}

3.1. Fourier Transform Infrared Spectra (FTIR). Figure 2 shows the FTIR of APC, SG, and SGAPC. The infrared spectrum (Figure 2(a)) shows the following absorptions: 3428 and $3137 \mathrm{~cm}^{-1}\left(\nu_{s}-\mathrm{NH}\right), 2903 \mathrm{~cm}^{-1}\left(\nu_{s}-\mathrm{CH}\right), 1610$ and $1583 \mathrm{~cm}^{-1}\left(\delta_{s}-\mathrm{NH}\right)$, and $1106 \mathrm{~cm}^{-1}\left(\nu_{s}-\mathrm{Si}-\mathrm{O}-\mathrm{Si}\right)$. These bands are considered very important and are consistent with those expected and described in the literature for the APC [20, 21].

The absorptions observed at 565 and $500 \mathrm{~cm}^{-1}$ are deformations of the silsesquioxane skeleton. The two bands near $3500 \mathrm{~cm}^{-1}$ (3137 and $\left.3428 \mathrm{~cm}^{-1}\right)$ and another intense band at $1610 \mathrm{~cm}^{-1}$ assigned to the symmetric stretching $\mathrm{NH}$ and $\mathrm{NH}$ angular deformations are characteristic of primary amines. Other bands in the regions of 400 and $900 \mathrm{~cm}^{-1}$ were attributed to the angular deformation of the $\mathrm{NH}$ group. Table 1 shows the main absorptions and their assignments.

A broad absorption caused by the symmetric stretching $\mathrm{Si}-\mathrm{O}-\mathrm{Si}\left[\nu_{s}(\mathrm{Si}-\mathrm{O})\right]$ at about $1100 \mathrm{~cm}^{-1}$ and the angular deformations of the skeleton of silsesquioxane were observed, one near 565 and another at $400 \mathrm{~cm}^{-1}$; moreover, they are typical of silsesquioxanes-shaped cages $[22,23]$.

Figure 2(b) shows the absorption spectrum of SG. The spectrum of SG shows a band near $3750 \mathrm{~cm}^{-1}$ which was attributed to stretching of the surface silanol groups [24]. 


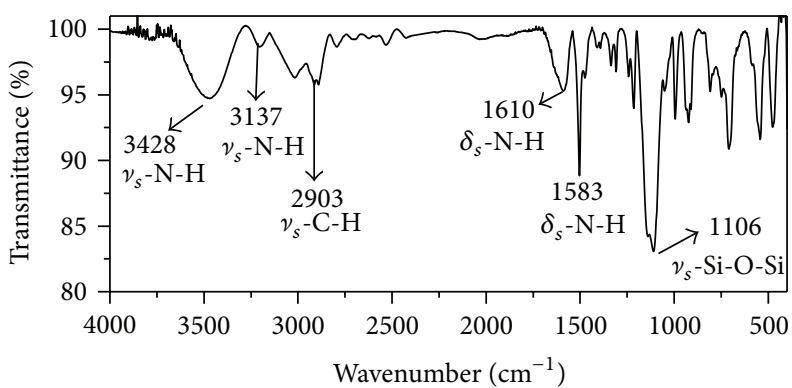

(a)



(b)

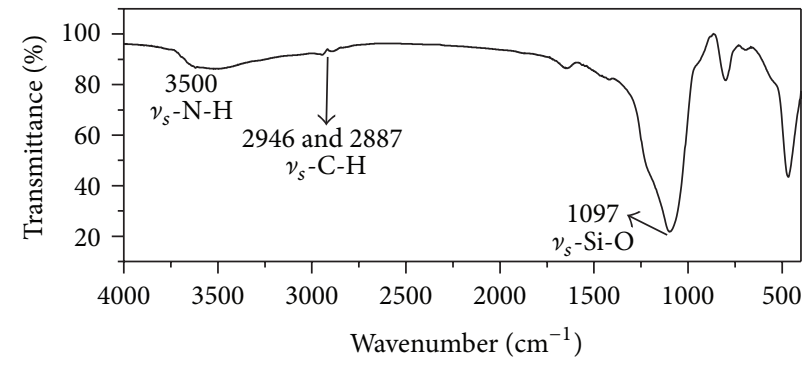

(c)

FIGURE 2: Vibrational spectrum for (a) APC; (b) SG; (c) SGAPC.

TABLE 1: Bands assigned in the FTIR spectrum for SGAPC.

\begin{tabular}{lcc}
\hline Functional Group & Wavenumber $\left(\mathrm{cm}^{-1}\right)$ & Type of vibration \\
\hline Si-C & 1250 & $v_{s}$ \\
Si-O-Si & 1110 at 1030 & $v_{s}$ \\
$\mathrm{~N}-\mathrm{H}$ & 1650 at 1580 & $\delta_{s}$ \\
$\mathrm{~N}-\mathrm{H}$ & 3400 at 3500 & $v_{s}$ \\
\hline
\end{tabular}

* $v_{s}$ symmetric stretching; $\delta_{s}$ angular deformation.

In the region between 3700 and $3200 \mathrm{~cm}^{-1}$, a broadband corresponding to symmetric stretching vibrations of $\mathrm{Si}-\mathrm{OH}$ group was observed. Absorptions related to the combination of the silica skeleton occur in the region between 2000 and $1870 \mathrm{~cm}^{-1}$. Other bands at 1630 and $3350 \mathrm{~cm}^{-1}$ were attributed to angular deformation of the water molecule [25], and the region below $1300 \mathrm{~cm}^{-1}$ was attributed to asymmetric vibrations of the Si-O-Si chain.

The spectrum in the infrared region of pure silica gel exerts limitations for characterizing the organofunctional groups chemically bound to the surface [25], such as physical affinity for water, low amount of organic material on the surface and also the absorption of the matrix (silica gel), which obscure the absorptions of the functional group in some regions of the spectrum, for example, absorption in the region of $3445 \mathrm{~cm}^{-1}\left(v_{\mathrm{C}-\mathrm{N}}\right)$.

Figure 2(c) illustrates the vibrational spectrum of SGAPC. Two bands at 2887 and $2946 \mathrm{~cm}^{-1}$ attributed to $\nu(\mathrm{CH})$ of $\mathrm{CH}_{2}$ groups are observed in the spectrum. The peak near at $750 \mathrm{~cm}^{-1}$ was attributed bending vibration of $\mathrm{Si}-\mathrm{C}$ bonding in $\mathrm{Si}-\mathrm{CH}_{2}$ [26]. Another band was observed at $1097 \mathrm{~cm}^{-1}$ which refers to the $v_{s}(\mathrm{Si}-\mathrm{O})$ of the $\mathrm{Si}-\mathrm{O}-\mathrm{Si}$ group of APC. The broad band in the region of $3500 \mathrm{~cm}^{-1}$ was assigned to the symmetric $\mathrm{NH}$ stretch of the peripheral groups $\mathrm{NH}_{2}$. The FTIR of SGAPC indicates that the main sites of the precursor remained after the functionalization.

3.2. Solid State Nuclear Magnetic Resonance (NMR) Analyses. The $\mathrm{Si}$ atom in the silicates can exhibit different chemical sites, which are subdivided into five groups described as $Q^{0}, Q^{1}$, $\mathrm{Q}^{2}, \mathrm{Q}^{3}, \mathrm{Q}^{4}$ [27].

The spectra of ${ }^{29} \mathrm{Si}$ and ${ }^{13} \mathrm{C}$ NMR of the APC are represented in Figures 3(a) and 3(b), respectively, The only sharp symmetrical peak $(-67.26 \mathrm{ppm})$ in ${ }^{29} \mathrm{Si} \mathrm{NMR}$ and three characteristic peaks in ${ }^{13} \mathrm{C}$ NMR spectra indicate that $\left[\mathrm{H}_{2} \mathrm{~N}\left(\mathrm{CH}_{2}\right)_{3}\right]_{8} \mathrm{Si}_{8} \mathrm{O}_{12}$, which has a cage-like structure, was successfully synthesized. The three $\mathrm{CH}_{2}$ groups $(\alpha, \beta, \gamma)$ to the terminal silicon atom were clearly seen in ${ }^{13} \mathrm{C}$-NMR $\left(\alpha-\mathrm{CH}_{2}\right.$ at $10.18, \beta-\mathrm{CH}_{2}$ at 21.67 , and $\gamma-\mathrm{CH}_{2}$ at $\left.43.19 \mathrm{ppm}\right)$. Anal calcd for APC: Theoretical value C: $32.73 \%, \mathrm{H}: 7.27 \%$, N: $12.73 \%$. Measurement value C: $32.75 \%, \mathrm{H}: 7.32 \%$, N: $12.71 \%$. These results are consistent with those observed in the literature $[20,21]$ and confirm the formation of APC.

The spectra of ${ }^{29} \mathrm{Si}$ and ${ }^{13} \mathrm{C}$ NMR of SGAPC are illustrated in Figure 4. The ${ }^{29} \mathrm{Si}$ spectrum (Figure 4(a)) of SGAPC showed four peaks at $-59.47,-67.05,-97.17$, and $-113.56 \mathrm{ppm}$. The peaks -97.17 and $-113.56 \mathrm{ppm}$ were assigned to units in $\mathrm{Q}^{3}$ and $\mathrm{Q}^{4}$ in the silica, respectively. The peak at $-59.47 \mathrm{ppm}$ was assigned to $\left(\mathrm{SiO}_{2}\right)$ and $\mathrm{ROCH}_{3}$ peak at $-67.05 \mathrm{ppm}$ $\mathrm{R}\left(\mathrm{SiO}_{2}\right) \mathrm{O}\left(\mathrm{SiO}_{2}\right) \mathrm{R}$, where $\mathrm{R}$ represents the modifier support. The spectrum of the ${ }^{13} \mathrm{C}$ SGAPC (Figure 4(b)) showed nine types of resonance $(9.21,10.18,21.18,23.45,27.33,42.06$, $44.33,48.37$, and $51.29 \mathrm{ppm})$. The peaks at 10.18, 21.18, 27.33, 48.37, and $51.29 \mathrm{ppm}$ were attributed to nonreactive SG 


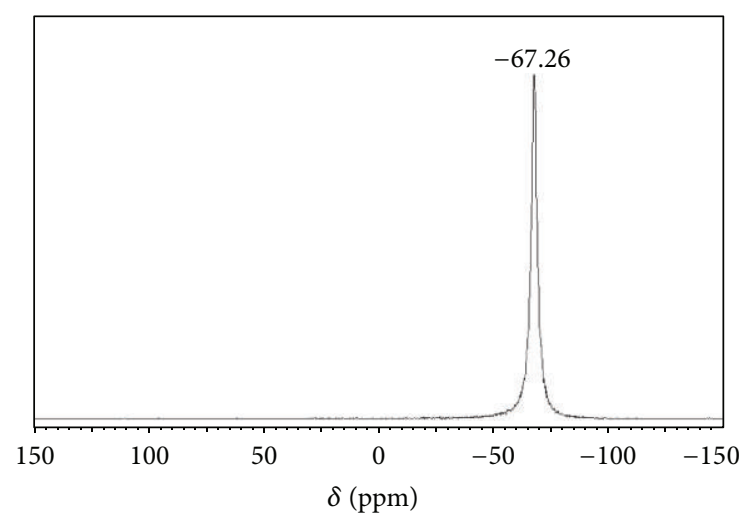

(a)

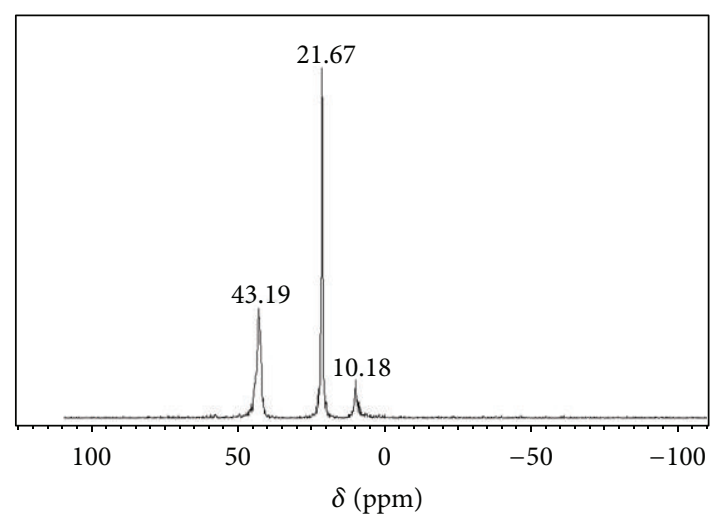

(b)

Figure 3: NMR solid state for APC: (a) ${ }^{29} \mathrm{Si}$; (b) ${ }^{13} \mathrm{C}$.

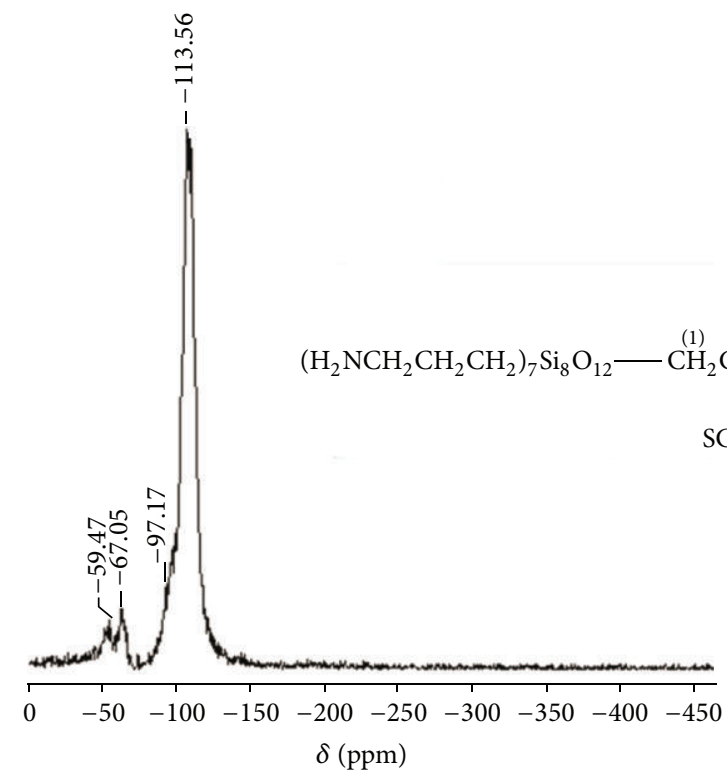

(a)

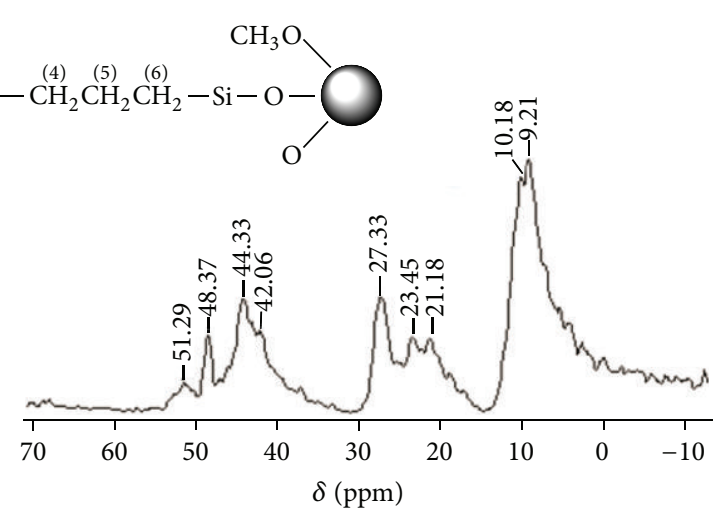

(b)

FIGURE 4: NMR solid state for SGAPC: (a) ${ }^{29} \mathrm{Si}$; (b) ${ }^{13} \mathrm{C}$.

sites, possibly due to a steric hindrance. According to the literature [28], peaks 9.21, 23.45, 42.06, and $44.33 \mathrm{ppm}$ were tentatively assigned to carbons (3) and (6), (2) and (5) (1), (4), respectively. Judging by the presence and shifting of the resonance peaks observed for the ${ }^{13} \mathrm{C}$, it can be stated that the APC functionalization of the silica gel surface occurred.

3.3. Porosity and Surface Area. The pore size distribution provides a deeper insight into the reactivity of free silanol groups available for reaction with other molecules [29], which explains the sorption characteristics of molecules. The characterization of porosity by means of sorption isotherms of $\mathrm{N}_{2}$ at $-196^{\circ} \mathrm{C}$ was used to determine the pore size distribution of samples containing micropores ( 0.5 to $2.5 \mathrm{~nm})$ and mesopores (2.5 to $100 \mathrm{~nm}$ ).
Different types of hysteresis are found in the literature [30]; the untreated silica gel has the shape of type IV isotherm with $\mathrm{H} 1$ type hysteresis. This hysteresis type is often found for solids containing spherical mesopore particle clusters with regular order and size, with uniform pores in the cross section, and only small variations along the longitudinal direction.

Figure 5(a) illustrates a comparison of the hysteresis of SG and SGAPC in its cavities, respectively, which is related to a low setting of the shape and size of pores. This fact is attributed to the nonuniformity of the conical-shaped pore opening, with the filling and emptying (sorption and desorption) of the pores. The inflection curve $\left(P / P_{0}\right)$ for the SG starts at 0.42 and runs up to 0.84 . This value is almost the same for SGAPC (0.45 to 0.89), which is common for the type $\mathrm{H} 1$ hysteresis. After the modification, a decrease of approximately $100 \mathrm{~m}^{2} \mathrm{~g}^{-1}$ was observed in the surface area 


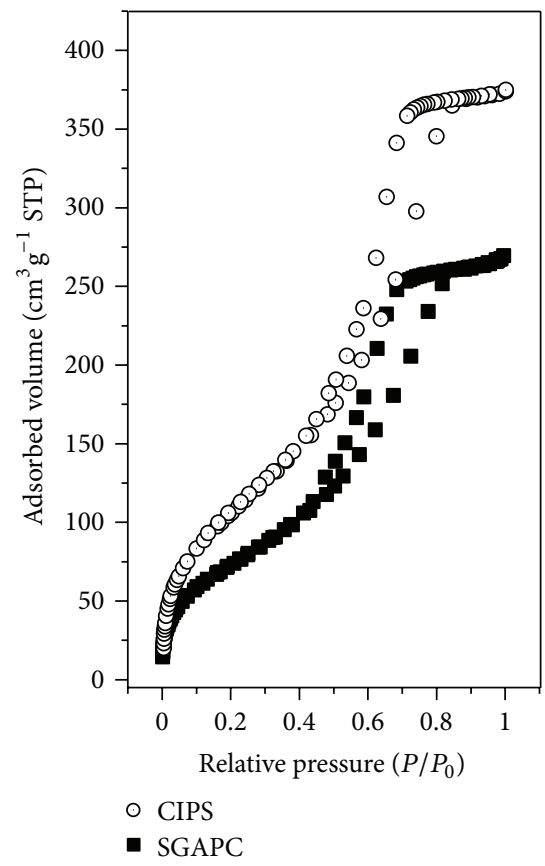

(a)

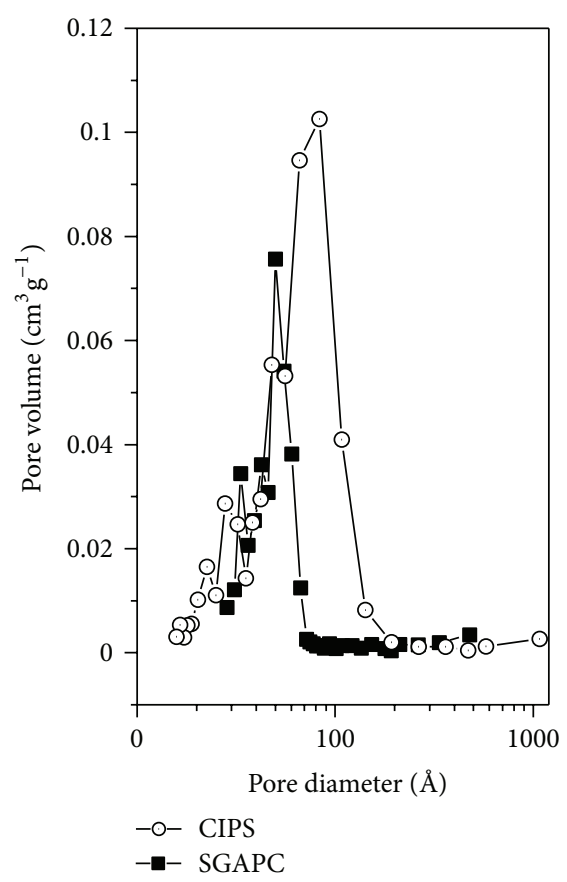

(b)

FIGURE 5: $\mathrm{N}_{2}$ adsorption/desorption iso terms at $77 \mathrm{~K}$ (a) and pore size distributions (b) for ClPS and SGAPC.

TABLE 2: Structural parameters for CIPS and SGAPC.

\begin{tabular}{lccc}
\hline Sample & $\begin{array}{c}\text { Surface Area } \\
\left(\mathrm{m}^{2} \mathrm{~g}^{-1}\right)\end{array}$ & $\begin{array}{c}\text { Pore volume } \\
\left(\mathrm{cm}^{3} \mathrm{~g}^{-1}\right)\end{array}$ & $\begin{array}{c}\text { Average pore size } \\
4 V / A\end{array}$ \\
\hline ClPS & 380.64 & 0.59 & 42.8 \\
SGAPC & 278.10 & 0.25 & 25.4 \\
\hline
\end{tabular}

(BET) of the SG (Table 2), and this area reduction may be related to an obstruction of the free access to nitrogen in the pores of the SG. According to Figure 5(b) and Table 2, there was a size and volume decrease of the pore size; therefore, these factors indicate that the molecules immobilized in the silica occupy part of the pore, thereby hindering accessibility to the silica surface.

3.4. Nitrogen Analysis. The nitrogen analysis of the SGAPC, using the Kjeldahl nitrogen determination method, showed that it has $1.95 \%$ nitrogen per gram, enabling to estimate the number of groups linked per unit of material. For each molecule linked to the silica surface there are eight nitrogen atoms in its structure, thus dividing the percentage of nitrogen obtained in the elemental analysis by the molecular weight of nitrogen contained in a molecule $\left(1.95 \times 10^{-2} / 8 \times\right.$ $\left.14 \mathrm{~g} \mathrm{~mol}^{-1}\right)$; the result is $1.74 \times 10^{-4}$ moles of nitro groups per gram of functionalized material $\left(N_{0}\right)$.

As the modifier molecules are uniformly distributed and linked on the silica surface, one can express the degree of functionalization of SGAPC to the quantity of functional groups attached onto the surface per unit area [31], that is, the surface density of the molecules $(d)$ can be determined by $d=N \times N_{0} / S_{\mathrm{BET}}$, where $N$ is the Avogadro number and $S_{\mathrm{BET}}$ is the surface area, $\mathrm{nm}^{2} \mathrm{~g}^{-1}$.

Knowing the surface density of the molecules $(d)$ and area $(S)$ occupied by an APC molecule obtained by $S=1 / d$, the average distance $(L)$ between the molecules on the SGAPC surface can be estimated. This enables to better understand the disposition of organofunctionalized molecules on the substrate. It is assumed, arbitrarily, a square space on the surface, with the $S$ area given by $L^{2}$, where $L=S^{1 / 2}$ is the average distance between the molecules.

For SGAPC with $N_{0}=1.74 \times 10^{-4} \mathrm{molg}^{-1}$ and $S_{\text {BET }}=$ $278.10 \mathrm{~m}^{2} \mathrm{~g}^{-1}$ and d of 0.377 molecule $\mathrm{nm}^{-2}$ and $L=1.6 \mathrm{~nm}$. Then, the average distance between two nitrogen groups linked at SGAPC is $1.6 \mathrm{~nm}$, considering that the functional groups are attached perpendicularly onto the surface.

3.5. Sorption Study. Sorption in a solution containing metal ions is a process that results in the preconcentration of ions on the surface of a solid phase, called the adsorbent [32]. Complete sorption can be quantitatively described by the sorption, isotherms, with constant temperature, which provides data related to the amount adsorbed $\left(N_{f}\right)$ and the concentration of solute $(C)$, once equilibrium is reached [33].

In the study of sorption, the equilibrium time of the sorption of $\mathrm{Cu}^{2+}$ for SGAPC was first determined by the curves of sorption isotherms of the $N_{f} / C$ ratio for the aforementioned system.

The curves of sorption equilibrium time are represented by $S_{f}$ with its respective time (minutes). The kinetic study of sorption determines the time required for the sorption of $\mathrm{Cu}^{2+}$ ions for SGAPC in one specific solvent, with constant 


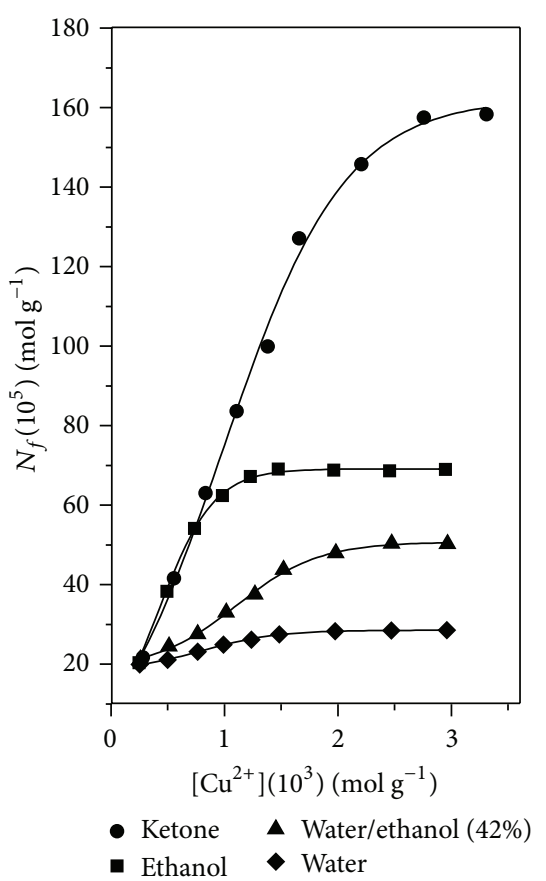

(a)

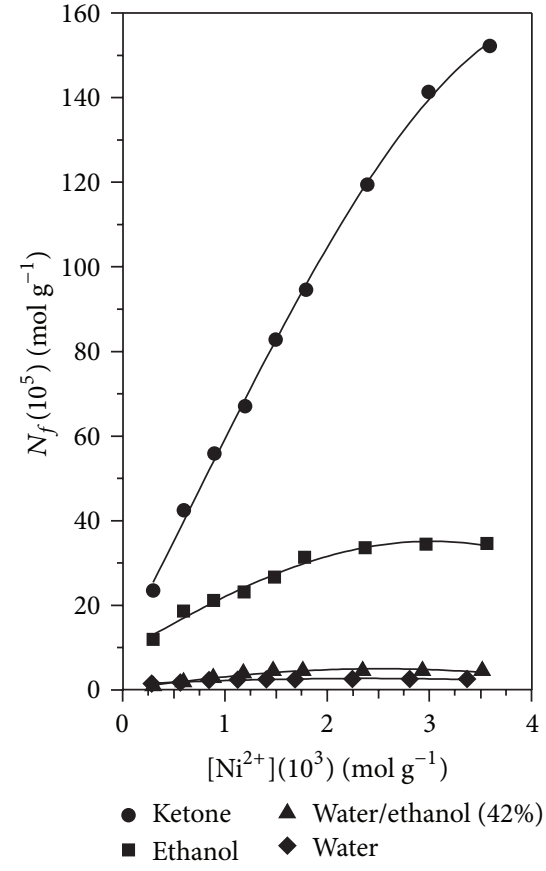

(b)

FIGURE 6: Adsorption isotherms of copper (a) and nickel (b) ions from solutions on SGAPC at $25^{\circ} \mathrm{C}$.

temperature $\left(25^{\circ} \mathrm{C}\right)$. Through kinetic studies, it was found that the required time for reaction to occur is $30 \mathrm{~min}$, but the time used in the following studies was $35 \mathrm{~min}$, in order to have an acceptable margin of safety time, and this one was close to that observed for other solvents such as ketone, ethanol, and ethanol/water $42 \%$.

The SGAPC acts as a complexing agent (sequestrant) of chemical species (metallic ions) in ethanol, ketone, and hydroalcoholic aqueous media. This is due to the presence of terminal amine groups in their structures, and this functional group has affinity with metal ions.

The experimental results are expressed by the sorption isotherms obeying the relation $N_{f} / C$. The maximum number of moles of adsorbed metal ions $\left(N_{f}^{\text {máx }}\right)$, called the specific sorption capacity [34], is equal to the number of moles of metal ions adsorbed when the concentration $(C)$ of the metal tends to the saturation limit (1),

$$
N_{f}^{\operatorname{máx}}=\lim _{c \rightarrow \infty}\left|N_{f}\right| \text {. }
$$

The quantity of adsorbed metal, $N_{f}$ in each flask was determined by the following:

$$
N_{f}=\frac{\left(N_{a}-N_{s}\right)}{m},
$$

where $m$ is the mass of the adsorbent (SGAPC) and $N_{a}$ and $N_{s}$ are the initial and the equilibrium amount of the number of moles of the metal in the solution phase, respectively. $W$ is the adsorbent mass (SGAPC).

Figure 6 shows the results of the sorption of $\mathrm{Cu}^{2+}$ and $\mathrm{Ni}^{2+}$ for SGAPC. Figure 6(a) shows the saturation of SGAPC sites of about $\mathrm{Cu}^{2+}$ concentration of $2.0 \times 10^{-3} \mathrm{~mol} \mathrm{~L}^{-1}$ for aqueous, ethanol, and water/ethanol $42 \%$ and around $2.7 \times$ $10^{-3} \mathrm{~mol} \mathrm{~L}^{-1}$ in the ketone medium under the conditions used. Figure 6(b) shows that the saturation of SGAPC sites with $\mathrm{Ni}^{2+}$ was of about $2.2 \times 10^{-3} \mathrm{~mol} \mathrm{~L}^{-1}$ for aqueous, ethanol, and water/ethanol $42 \%$; interestingly in the ketone medium, in the concentration range studied, the active sites of SGAPC were not saturated. According to the sorption study, it was observed that the sorption capacity of the material by $\mathrm{Cu}^{2+}$ and $\mathrm{Ni}^{2+}$ in ketone is higher than that in the other solvents investigated.

Parts of the peripheral groups of APC in SGAPC are covalently bonded to the surface of 3-chloropropyl silica gel. The groups that are free on the surface of the modified silica adsorb $\mathrm{MCl}_{2}\left(\mathrm{M}=\mathrm{Cu}^{2+} ; \mathrm{Ni}^{2+}\right)$ in aqueous and nonaqueous solvents; thus, the metal complex forming on the surface of the matrix and the presence of nucleophilic centers are what gives modified silica the capacity to adsorb metal ions from the solution [35].

Equation (3) illustrates a schematic representation of the equilibrium that occurs in SGAPC with $\mathrm{MCl}_{2}$, respectively:

$$
\begin{aligned}
\operatorname{SGAPC}_{(s)}+\mathrm{M}^{2+}+2 \mathrm{X}_{\text {solvent }}^{-} & \\
& \longleftrightarrow \mathrm{SGAPCMX}_{2(s)}, \quad \text { where } \mathrm{X}=\mathrm{Cl}^{-} .
\end{aligned}
$$

According to Andreotti [36], it is difficult to generalize the chemical nature of solute sorption, as it depends on the sorbent surface polarity and also on the solvent properties. The sorption from solutions involves at least three interaction forces: solute-solvent, solute-adsorbent, and 


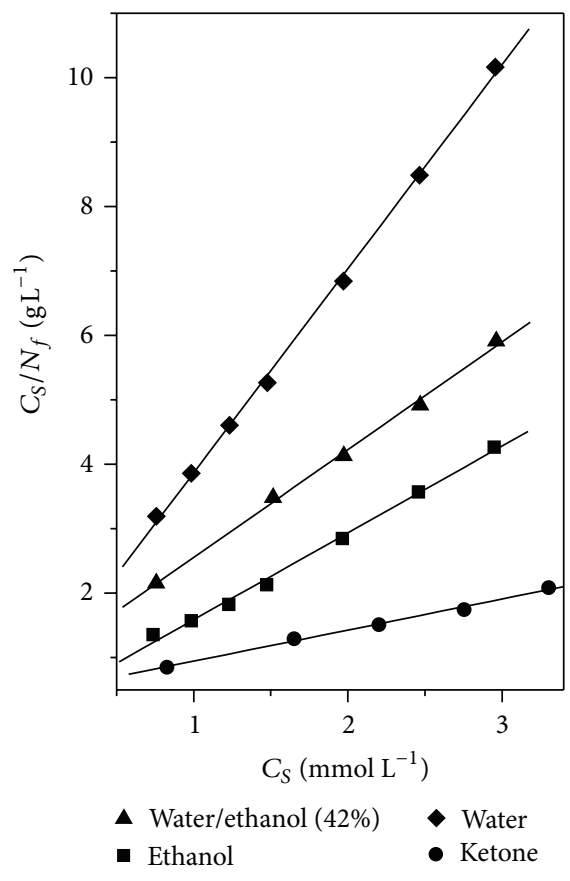

(a)

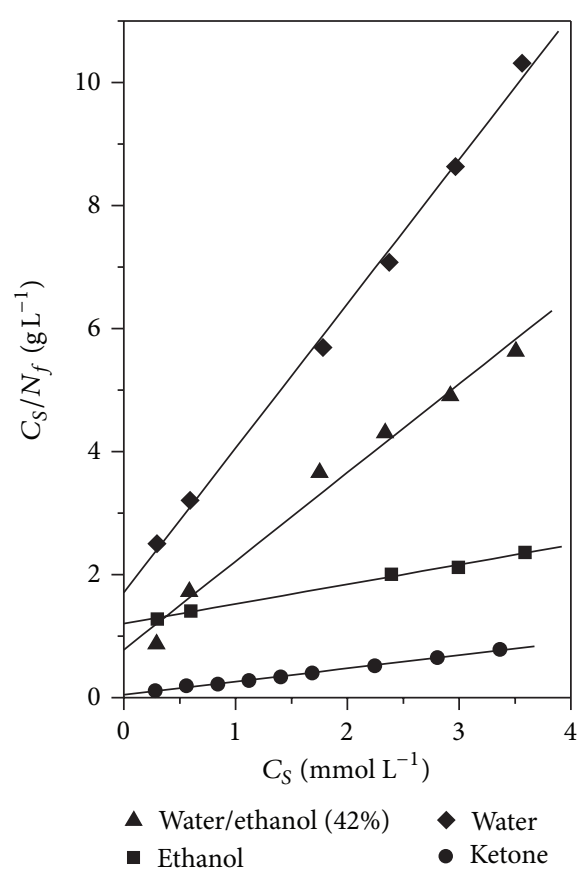

(b)

FIGURE 7: Adsorption isotherms of copper (a) and nickel (b) ions in several solvents solutions on SGAPC as plot of $C / N_{f}$ against $C_{S}$ at $25^{\circ} \mathrm{C}$.

solvent-adsorbent. In the sorption process, there is a competition between metal ions and the solvent molecules by the ligand groups immobilized on silica (adsorbent-solvent interaction). Other important factors to be considered are the solubility and solvation effects of ions resulting from solutesolvent interactions.

Comparing these results with those described in the literature, it was observed that the sorption capacity of SGAPC was higher than that of similar materials, such as, 3(4-amino-2-mercaptopyrimidine) propyl silica gel (AMSG) and 3-(2-mercaptopyrimidine) propyl silica gel (MPSG) [37], octa-(3-amino-1,2,4-triazolpropil) silsesquioxane (ATZ-SSQ), and 3-amino-1,2,4-triazole [38, 39]. The SGAPC showed better results on the sorption of $\mathrm{Cu}^{2+}$ and $\mathrm{Ni}^{2+}$ ions in comparison with similar materials in the literature, which shows the high sorption capacity of these new materials, as well as in future applications. Silica gel modified with thiadiazole and mercaptopyridine analogue compounds have the disadvantage of forming possible toxic derivates, thereby it is important to control the traces of these compounds, since the pyrimidine derivatives are used in various areas, namely, in the antibiotic and pesticide industry [40] and in biological systems [41].

3.6. Stability of the Complexes on the Surface of SGAPC. Assuming the monolayer formation on silica surface, the Langmuir equation (4) can be applied to linearize the adsorption isotherms and to estimate important parameters related to equilibrium solute-adsorbent-solvent,

$$
\frac{C_{S}}{N_{f}}=\frac{C_{S}}{N_{S}}+\frac{1}{N_{S} k} .
$$

$C_{S}$ represents the concentration of the solution at equilibrium in $\mathrm{mol} \mathrm{L}^{-1}, N_{f}$ is the adsorption capacity $\left(\mathrm{mol} \mathrm{g}^{-1}\right)$, $N_{s}$ is the maximum amount of solute adsorbed per gram of adsorbent $\left(\mathrm{molg}^{-1}\right)$, and $k$ is the measure of sorption intensity, which is related to the equilibrium constant. The relation of $C_{S} / N_{f}$ as a function of $C_{S}$ provides the $1 / N_{S}$ and $1 /\left(k N_{S}\right)$, which are the angular and linear coefficients, respectively, thereby making it possible to calculate the values of the constants $k$ and $N_{S}$ [39].

The adsorption capacity $N_{s}$ and the equilibrium constant $k$ were calculated by plotting $C / N_{f}$ against $C$ for SGAPC, according to Figure 7; the main calculated parameters for the sorption study in a solution of $\mathrm{Cu}^{2+}$ and $\mathrm{Ni}^{2+}$ for SGAPC are represented in Table 3 . According to Table 3, most of the solvents in the studies using $\mathrm{Cu}^{2+}$ and $\mathrm{Ni}^{2+}$ are in agreement with the Langmuir model, where the values of $N_{f}$ and $N_{S}$ are nearly equal in the saturation point of the surface.

The linearization of the isotherms enabled to calculate the sorption intensity of the complexes represented by the constant $k$. The high values of the constant in the order of $10^{3} \mathrm{~L} \mathrm{~mol}^{-1}$ suggest that the complexes formed on the surface of adsorbents are thermodynamically stable [39].

3.7. Application on Column Separation. The SGAPC showed slight graininess and no homogeneous particles, which hindered the preparation of the columns. The particles fit together in such a way that the channels formed are narrow, which can cause obstructions and difficulties to percolate the solutions; therefore, a $1 \mathrm{~cm}$ diameter column and $1 \mathrm{~cm}$ height packing and $0.5 \mathrm{~mL} \mathrm{~min}^{-1}$ elution speed were chosen. 
TABLE 3: Calculated parameters for the sorption of $\mathrm{Cu}^{2+}$ and $\mathrm{Ni}^{2+}$ onto SGAPC and values of $N_{f}$ and correlation coefficient $(R)$.

\begin{tabular}{|c|c|c|c|c|c|}
\hline Analyte & Solvent & $\begin{array}{c}N_{f}^{\text {máximo }} \\
10^{5}\left(\mathrm{~mol} \mathrm{~g}^{-1}\right)\end{array}$ & $\begin{array}{c}N_{S} \\
10^{5}\left(\mathrm{molg}^{-1}\right)\end{array}$ & $\begin{array}{c}K \\
10^{-3}\left(\mathrm{~L} \mathrm{~mol}^{-1}\right) \\
\end{array}$ & $R$ \\
\hline \multirow{4}{*}{$\mathrm{Cu}^{2+}$} & Water & 29.1 & 31.1 & 5.259 & 0.999 \\
\hline & Water/Ethanol 42\% & 50.1 & 58.5 & 2.160 & 0.999 \\
\hline & Ethanol & 69.1 & 74.2 & 5.585 & 0.998 \\
\hline & Ketone & 158.3 & 191.2 & 1.530 & 0.995 \\
\hline \multirow{4}{*}{$\mathrm{Ni}^{2+}$} & Water & 2.6 & 4.6 & 4.705 & 0.998 \\
\hline & Water/Ethanol $42 \%$ & 4.3 & 4.6 & 7.883 & 0.998 \\
\hline & Ethanol & 34.5 & 42.6 & 1.374 & 0.998 \\
\hline & Ketone & 152.1 & 313.1 & 0.265 & 0.998 \\
\hline
\end{tabular}

The previous recovery study was carried out using a solution containing $3.728 \mathrm{mg} \mathrm{L}^{-1} \mathrm{Cu}^{2+}$ in an alcohol medium of $42 \%(\mathrm{v} / \mathrm{v})$, since most of our real samples are alcohol based. Another study was conducted with a solution containing $0.500 \mathrm{mg} \mathrm{L}^{-1} \mathrm{Cu}^{2+}$ and $0.500 \mathrm{mg} \mathrm{L}^{-1}$ for $\mathrm{Ni}^{2+}$, also in ethanol medium of $42 \%$, in order to test the influence of nickel ions for the determination of $\mathrm{Cu}^{2+}$.

Table 4 shows the results of the recovery column performed with the solution of $3.728 \mathrm{mg} \mathrm{L}^{-1} \mathrm{Cu}^{2+}$ in a column packed with SGAPC. It can be observed that all the metal was eluted with hydrochloric acid $1.0 \mathrm{~mol} \mathrm{~L}^{-1}$ with a recovery percentage of around $100 \%$. The preconcentration factor $\left(F_{\mathrm{pc}}\right)$ calculated by (5) was 3.0 for the sample eluted with $3.0 \mathrm{~mL}$ of $\mathrm{HCl} 1.0 \mathrm{~mol} \mathrm{~L}^{-1}$,

$$
F_{\mathrm{pc}}=\frac{\left[\mathrm{Cu}^{2+}\right]_{\mathrm{eluted}}}{\left[\mathrm{Cu}^{2+}\right]_{\text {initial }}}
$$

Table 4 shows the recovery results with a mixture of solutions containing $0.500 \mathrm{mg} \mathrm{L}^{-1} \mathrm{Cu}^{2+}$ and $0.500 \mathrm{mg} \mathrm{L}^{-1}$ of $\mathrm{Ni}^{2+}$ for SGAPC. It should be noted that SGAPC had a $\mathrm{Cu}^{2+}$ recovery of about $71 \%\left(\mathrm{HCl} 1.0 \mathrm{~mol} \mathrm{~L}^{-1}\right)$, and this fact may be related to a higher selectivity of the complexes formed by nickel on the silica surface. Nickel ions can bond strongly to the organic group due to their greater selectivity, thereby reducing the binding of $\mathrm{Cu}^{2+}$. The $F_{\mathrm{pc}}$ value determined by (5) for the column with SGAPC was 10 and was calculated for the samples percolated with $\mathrm{HCl} 1.00 \mathrm{~mol} \mathrm{~L}^{-1}$. The other important fact is that SGAPC is not leached from the matrix, and its capacities were not affected after several retention/elution cycles for 7 months of continuous use, hence providing an excellent useful lifetime for the material.

Real samples of distilled spirits and ethanol fuel were percolated in columns in order to demonstrate the separation capability of $\mathrm{Cu}^{2+}$. For copper determination, the percolated samples were eluted with $3.0 \mathrm{~mL}$ of $\mathrm{HCl} 1.00 \mathrm{~mol} \mathrm{~L}^{-1}$, collected, and diluted at $5.0 \mathrm{~mL}$ in a volumetric flask. Table 5 shows the results for the column packed with SGAPC. For the Ginger brandy sample, a low recovery (84\%) was observed, probably due to an interaction of secondary organic products present in the matrix sample. By means of the preliminary chromatographic analysis, it was noted that this interaction was due to the difference in chromatographic (HPLC) profile
TABLE 4: Recovery of $\mathrm{Cu}^{2+}$ after percolation of $30.0 \mathrm{~mL}$ of solution in the column filled with SGAPC.

\begin{tabular}{lcccc}
\hline $\begin{array}{l}{\left[\mathrm{Cu}^{2+}\right]_{\text {initial }}} \\
\left(\mathrm{mg} \mathrm{L}^{-1}\right)\end{array}$ & $\begin{array}{c}{\left[\mathrm{Ni}^{2+}\right]_{\text {initial }}} \\
\left(\mathrm{mg} \mathrm{L}^{-1}\right)\end{array}$ & $\begin{array}{c}{[\mathrm{HCl}]} \\
(\mathrm{mol} \mathrm{L})\end{array}$ & $\begin{array}{c}{\left[\mathrm{Cu}^{2+}\right]_{\text {eluted }}} \\
\left(\mathrm{mg} \mathrm{L}^{-1}\right)\end{array}$ & $\begin{array}{c}\text { Recovery } \\
\left(\mathrm{Cu}^{2+}\right)(\%)\end{array}$ \\
\hline 3.728 & 0 & 0.01 & $0.100 \pm 0.003$ & $2.7 \pm 0.3$ \\
3.728 & 0 & 0.10 & $1.195 \pm 0.011$ & $32.1 \pm 1.1$ \\
3.728 & 0 & 0.50 & $3.567 \pm 0.012$ & $95.7 \pm 1.2$ \\
3.728 & 0 & 1.00 & $3.753 \pm 0.009$ & $100.6 \pm 0.9$ \\
0.500 & 0.500 & 0.01 & $0.006 \pm 0.004$ & $1.2 \pm 0.4$ \\
0.500 & 0.500 & 0.10 & $0.007 \pm 0.003$ & $1.4 \pm 0.3$ \\
0.500 & 0.500 & 0.50 & $0.302 \pm 0.010$ & $60.0 \pm 1.0$ \\
0.500 & 0.500 & 1.00 & $0.355 \pm 0.014$ & $71.0 \pm 1.4$ \\
\hline
\end{tabular}

TABLE 5: Recovery of $\mathrm{Cu}^{2+}$ with $\mathrm{HCl} 1.0 \mathrm{~mol} \mathrm{~L}^{-1}$ after percolation of $100.0 \mathrm{~mL}$ of real samples in the column filled with SGAPC $(n=3)$.

\begin{tabular}{lccc}
\hline Real Samples & $\begin{array}{c}{\left[\mathrm{Cu}^{2+}\right]_{\text {added }}} \\
\left(\mathrm{mg} \mathrm{L}^{-1}\right)\end{array}$ & $\begin{array}{c}{\left[\mathrm{Cu}^{2+}\right]} \\
\left(\mathrm{mg} \mathrm{L}^{-1}\right)\end{array}$ & $\begin{array}{c}\text { Recovery } \\
(\%)\end{array}$ \\
\hline Sugar cane spirit & 0 & $0.198 \pm 0.005$ & - \\
& 0.050 & $0.246 \pm 0.004$ & $96 \pm 8.0$ \\
Vodka (38\%) & 0 & $0.013 \pm 0.002$ & - \\
Ginger brandy & 0.050 & $0.062 \pm 0.003$ & $98 \pm 6.0$ \\
Ethanol fuel & 0 & $0.023 \pm 0.007$ & - \\
& 0.050 & $0.065 \pm 0.006$ & $84 \pm 12.0$ \\
& 0 & $0.036 \pm 0.004$ & - \\
& 0.050 & $0.087 \pm 0.005$ & $102 \pm 10.0$ \\
\hline
\end{tabular}

observed before and after the percolation of the sample in the column containing SGAPC (results not shown).

\section{Concluding Remarks}

The functionalization of 3-chloropropyl silica gel with the Octa(3-aminopropyl)octasilsesquioxane was successfully prepared. In this study, using several techniques, it was observed that $\mathrm{Cu}$ (II) is adsorbed by surface amino groups of SGAPC. The SGAPC composite obtained proved to be quite promising in its use in sorption and preconcentration of $\mathrm{Cu}^{2+}$ and $\mathrm{Ni}^{2+}$ in several solvents and different samples. The Langmuir model allowed to describe the sorption of the metal 
ions on SGAPC, and the high values of the constant $(K)$ in the order of $10^{3} \mathrm{~L} \mathrm{~mol}^{-1}$ suggest that the complexes formed on the SGAPC surface are thermodynamically stable. The sorptiondesorption of the metal ions rendered possible to develop a method for the preconcentration and determination of metal ions at trace level in real samples, namely, fuel ethanol and beverages.

\section{Acknowledgment}

The financial support of this research was supplied by FAPESP (Foundation for Research Support of the State of São Paulo), processes 03/12882-6 and 2005/52173-0.

\section{References}

[1] R. H. Baney, M. Itoh, A. Sakakibara, and T. Suzuki, "Silsesquioxanes," Chemical Reviews, vol. 95, no. 5, pp. 1409-1430, 1995.

[2] K. L. Chan, P. Sonar, and A. Sellinger, "Cubic silsesquioxanes for use in solution processable organic light emitting diodes (OLED)," Journal of Materials Chemistry, vol. 19, no. 48, pp. 9103-9120, 2009.

[3] J. Wu and P. T. Mather, "POSS polymers: physical properties and biomaterials applications," Polymer Reviews, vol. 49, no. 1, pp. 25-63, 2009.

[4] M. G. Voronkov and V. L. Lavrent'yev, "Polyhedral oligosilsesquioxanes and their homo derivatives," Topics in Current Chemistry, vol. 102, pp. 199-236, 1982.

[5] A. Provatas and J. G. Matisons, "Silsesquioxanes: synthesis and applications," Trends in Polymer Science, vol. 5, pp. 327-332, 1997.

[6] Y. Gushikem, E. V. Benvenutti, and Y. V. Kholin, "Synthesis and applications of functionalized silsesquioxane polymers attached to organic and inorganic matrices," Pure and Applied Chemistry, vol. 80, no. 7, pp. 1593-1611, 2008.

[7] H. C. L. Abbenhuis, "Advances in homogeneous and heterogeneous catalysis with metal-containing silsesquioxanes," Chemistry, vol. 6, no. 1, pp. 25-32, 2000.

[8] F. J. Feher and T. L. Tajima, "Synthesis of a molybdenumcontaining silsesquioxane which rapidly catalyzes the metathesis of olefins," Journal of the American Chemical Society, vol. 116, no. 5, pp. 2145-2146, 1994.

[9] W. A. Herrmann, R. Anwander, V. Dufaud, and W. Scherer, "Molecular siloxane complexes of rare earth metals-model systems for silicate-supported catalysts?" Angewandte Chemie, vol. 33, no. 12, pp. 1285-1286, 1994.

[10] J. Liu, S. R. Wilson, J. R. Shapley, and F. J. Feher, "A triosmium cluster-siloxane cage complex. Synthesis and structure of $\mathrm{HOs}_{3}(\mathrm{CO})_{10}\left[(\mu-\mathrm{O}) \mathrm{Si}_{7} \mathrm{O}_{10}\left(\mathrm{C}_{6} \mathrm{H}_{11}\right)_{7}\right]$," Inorganic Chemistry, vol. 29, no. 26, pp. 5138-5139, 1990.

[11] Y. Wu and S. Kuo, "Synthesis and characterization of polyhedral oligomeric silsesquioxane (POSS) with multifunctional benzoxazine groups through click chemistry," Polymer, vol. 51, no. 17, pp. 3948-3955, 2010.

[12] K. Xie, Y. Wang, and L. Xu, "Modification of cellulose with reactive polyhedral oligomeric silsesquioxane and nano-crosslinking effect on color properties of dyed cellulose materials," Carbohydrate Polymers, vol. 80, no. 2, pp. 481-485, 2010.

[13] W. Zhang and A. H. E. Müller, "Synthesis of tadpole-shaped POSS-containing hybrid polymers via 'click chemistry,' Polymer, vol. 51, no. 10, pp. 2133-2139, 2010.
[14] D. R. do Carmo, G. R. de Castro, M. A. U. Martines, N. L. D. Filho, and N. R. Stradiotto, "Adsorption and electropolymerization of toluidine blue on the nanostructured octakis (hydridodimethylsiloxy)octasilsesquioxane surface," Materials Research Bulletin, vol. 43, no. 12, pp. 3286-3296, 2008.

[15] A. M. S. Lucho, F. L. Pissetti, and Y. Gushikem, " $\mathrm{Al}_{2} \mathrm{O}_{3}$-coated 3-N-propylpyridinium chloride silsesquioxane polymer film: preparation and electrochemical property study of adsorbed cobalt tetrasulfophthalocyanine," Journal of Colloid and Interface Science, vol. 275, no. 1, pp. 251-256, 2004.

[16] BRASIL, Decreto no 2314 of the 4 of september of 1997. Diário Oficial da União 171 (5 of sept., 1997) 19556.

[17] E. A. Neves, A. Oliveira, A. P. Fernandes, and J. A. Nóbrega, "Simple and efficient elimination of copper(II) in sugar-cane spirits," Food Chemistry, vol. 101, no. 1, pp. 33-36, 2006.

[18] G. F. Riedel, "Copper," in Encyclopedia of Ecology, S. E. Jorgensen and B. Fath, Eds., pp. 778-783, Elsevier, Oxford, UK, 2008.

[19] D. R. Do Carmo, L. L. Paim, G. Metzker, N. L. Dias Filho, and N. R. Stradiotto, "A novel nanostructured composite formed by interaction of copper octa(3-aminopropyl)octasilsesquioxane with azide ligands: preparation, characterization and a voltammetric application," Materials Research Bulletin, vol. 45, no. 9, pp. 1263-1270, 2010.

[20] F. J. Feher, K. D. Wyndham, D. Soulivong, and F. Nguyen, "Syntheses of highly functionalized cube-octameric polyhedral oligosilsesquioxanes $\left(\mathrm{R}_{8} \mathrm{Si}_{8} \mathrm{O}_{12}\right)$," Journal of the Chemical Society, no. 9, pp. 1491-1498, 1999.

[21] F. J. Feher, D. Soulivong, and F. Nguyen, "Practical methods for synthesizing four incompletely condensed silsesquioxanes from a single $\mathrm{R}_{8} \mathrm{Si}_{8} \mathrm{O}_{12}$ framework," Chemical Communications, no. 12, pp. 1279-1280, 1998.

[22] D. R. do Carmo, N. L. Dias Filho, and N. R. Stradiotto, "Synthesis and preliminary characterization of octakis(chloropropyldimethylsiloxy)octasilsesquioxane," Materials Research, vol. 7, pp. 499-504, 2004.

[23] D. R. do Carmo, L. L. Paim, N. L. Dias Filho, and N. R. Stradiotto, "Preparation, characterization and application of a nanostructured composite: octakis(cyanopropyldimethylsiloxy)octasilsesquioxane," Applied Surface Science, vol. 253, no. 7, pp. 3683-3689, 2007.

[24] C. Fulcher, M. A. Crowell, R. Bayliss, K. B. Holland, and J. R. Jezorek, "Synthetic aspects of the characterization of some silica-bound complexing agents," Analytica Chimica Acta, vol. 129, pp. 29-47, 1981.

[25] R. K. Iler, The Chemistry of Sílica, John Willey and Sons, New York, NY, USA, 1979.

[26] T. Lu, G. Liang, K. Kou, and Z. Guo, "Review synthesis and characterization of cage octa(cyclohexylsilsesquioxane)," Journal of Materials Science, vol. 40, no. 18, pp. 4721-4726, 2005.

[27] P. G. Harrison, "Silicate cages: precursors to new materials," Journal of Organometallic Chemistry, vol. 542, no. 2, pp. 141-183, 1997.

[28] G. Stephen Caravajal, D. E. Leyden, G. R. Quinting, and G. E. Maciel, "Structural characterization of (3-aminopropyl) triethoxysilane-modified silicas by silicon-29 and carbon-13 nuclear magnetic resonance," Analytical Chemistry, vol. 60, no. 17, pp. 1776-1786, 1988.

[29] P. K. Jal, S. Patel, and B. K. Mishra, "Chemical modification of silica surface by immobilization of functional groups for extractive concentration of metal ions," Talanta, vol. 62, no. 5, pp. 1005-1028, 2004. 
[30] E. P. Barrett, L. G. Joyner, and P. P. Halenda, "The determination of pore volume and area distributions in porous substances. I. Computations from nitrogen isotherms," Journal of the American Chemical Society, vol. 73, no. 1, pp. 373-380, 1951.

[31] N. L. Dias Filho, "Adsorption of copper(II) and cobalt(II) complexes on a silica gel surface chemically modified with 3amino-1,2,4-triazole," Colloids and Surfaces A, vol. 144, no. 1-3, pp. 219-227, 1998.

[32] N. Marmier, Encyclopedia of Surface and Colloid Science, Taylor \& Francis Group, New York, NY, USA, 2002.

[33] J. Tóth, "Encyclopedia of surface and colloid science," in Adsorption Isotherms, pp. 212-224, Budapest, Hungary, 2nd edition, 2002.

[34] N. L. Dias Filho, E. Rodrigues, and Y. Gushikem, "Structure of cobalt (II) perchlorate adsorbed on silica gel surface chemically modified with benzimidazole molecule," Journal of the Brazilian Chemical Society, vol. 8, no. 4, pp. 415-419, 1997.

[35] C. Airoldi and R. F. De Farias, "The use of organofuntionalized silica gel as sequestrating agent for metals," Quimica Nova, vol. 23, no. 4, pp. 496-503, 2000.

[36] I. E. Andreotti, Sílica gel funcionalizada com piperazinapropriedades de adsorção de íons metálicos em meio etanólico [Tese de mestrado], Instituto de Química, Campinas, Brazil, 1989.

[37] P. F. Britto, Sorption of Cu(II) íns on the surface of sílica gel modified with 4-amino-2-2-mercaptopyrimidine and mercaptopyrimidine [Dissertation], Faculdade de Engenharia de Ilha Solteira; Universidade Estadual Paulista, Ilha Solteira, Brazil, 2005.

[38] N. L. Dias Filho, R. M. Costa, F. Marangoni, and D. S. Pereira, "Nanoparticles of octakis[3-(3-amino-1,2,4triazole)propyl]octasilsesquioxane as ligands for $\mathrm{Cu}(\mathrm{II}), \mathrm{Ni}(\mathrm{II})$, $\mathrm{Cd}(\mathrm{II}), \mathrm{Zn}(\mathrm{II})$, and $\mathrm{Fe}(\mathrm{III})$ in aqueous solution," Journal of Colloid and Interface Science, vol. 316, no. 2, pp. 250-259, 2007.

[39] A. H. Rosa, D. Goveia, I. C. Bellin, S. Da Silva Lessa, N. L. Dias Filho, and P. De Magalhães Padilha, "New analytical procedure based on a cellulose bag and ionic exchanger with paminobenzoic acid groups for differentiation of labile and inert metal species in aquatic systems," Analytical and Bioanalytical Chemistry, vol. 386, no. 7-8, pp. 2153-2160, 2006.

[40] W. Ciesielski, R. Zakrzewski, A. Krenc, and J. Zielinska, "Iodimetric determination of 2-mercaptopyrimidines," Talanta, vol. 47, no. 3, pp. 745-752, 1998.

[41] J. Kurzawa, A. Wiśniewska, and K. Janowicz, "Stopped-flow determination of 2-mercaptopyrimidines as inductors of the iodine-azide reaction," Analytica Chimica Acta, vol. 567, no. 2, pp. 286-292, 2006. 

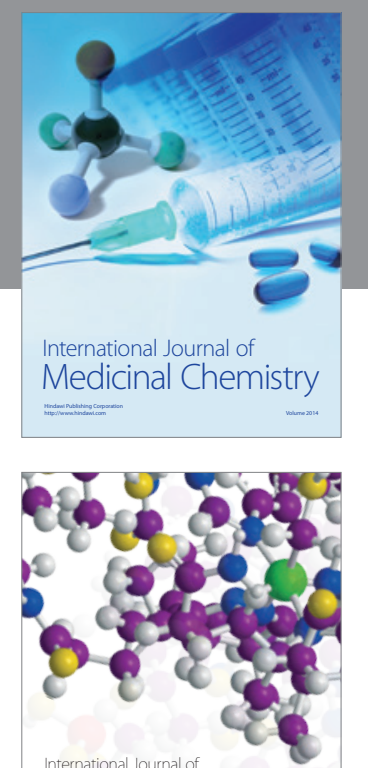

\section{Carbohydrate} Chemistry

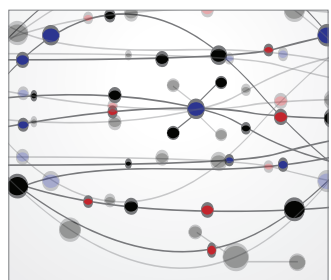

The Scientific World Journal

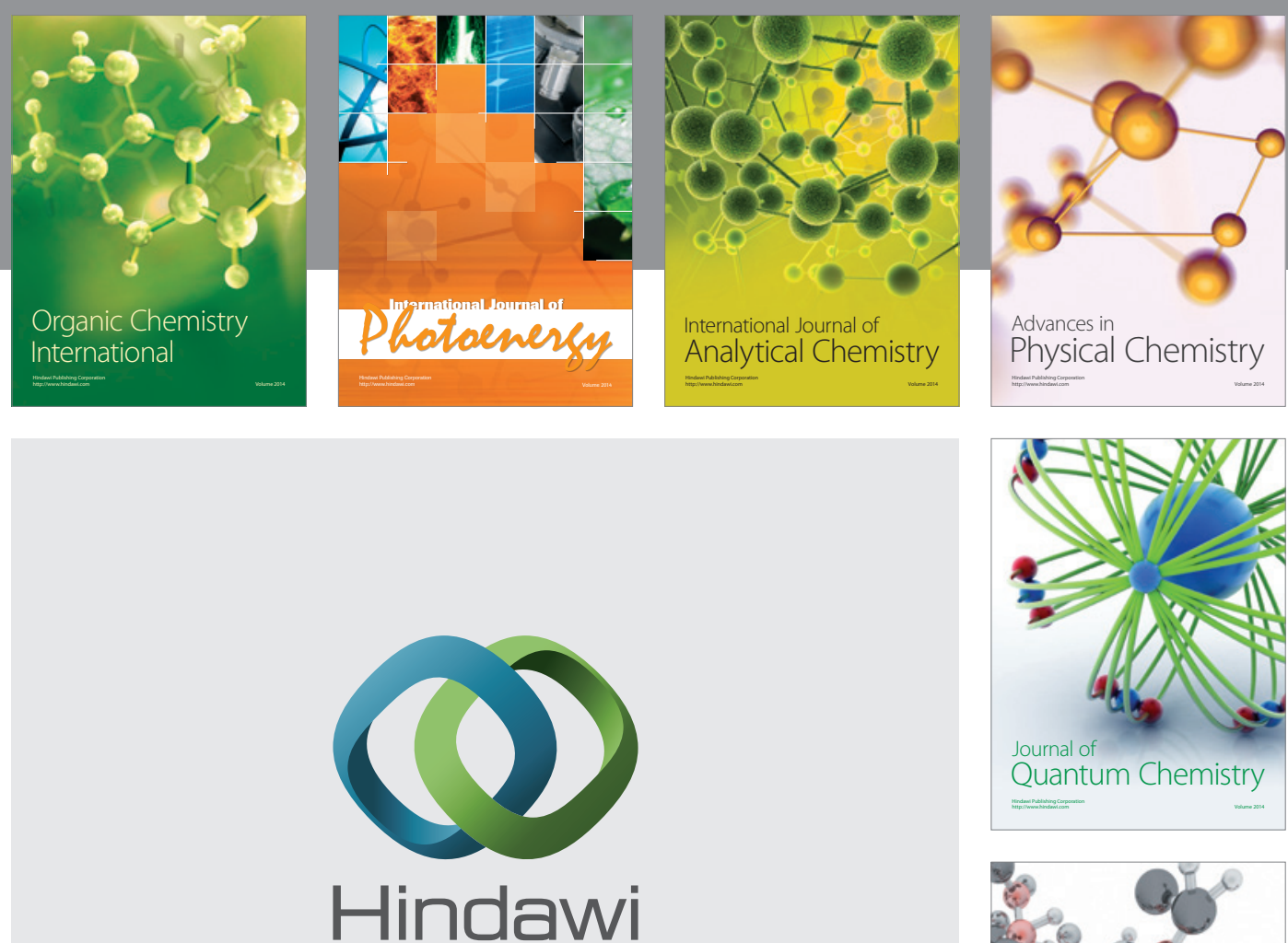

Submit your manuscripts at

http://www.hindawi.com

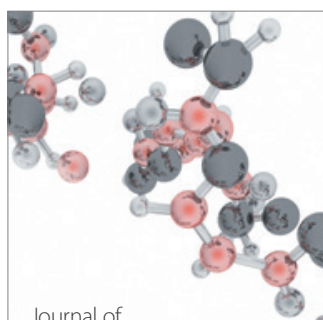

Analytical Methods

in Chemistry

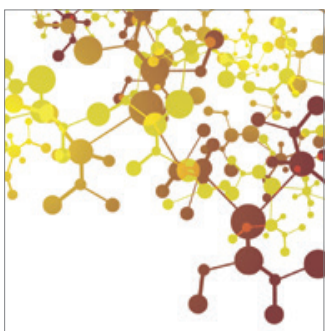

Journal of

Applied Chemistry



Inorganic Chemistry
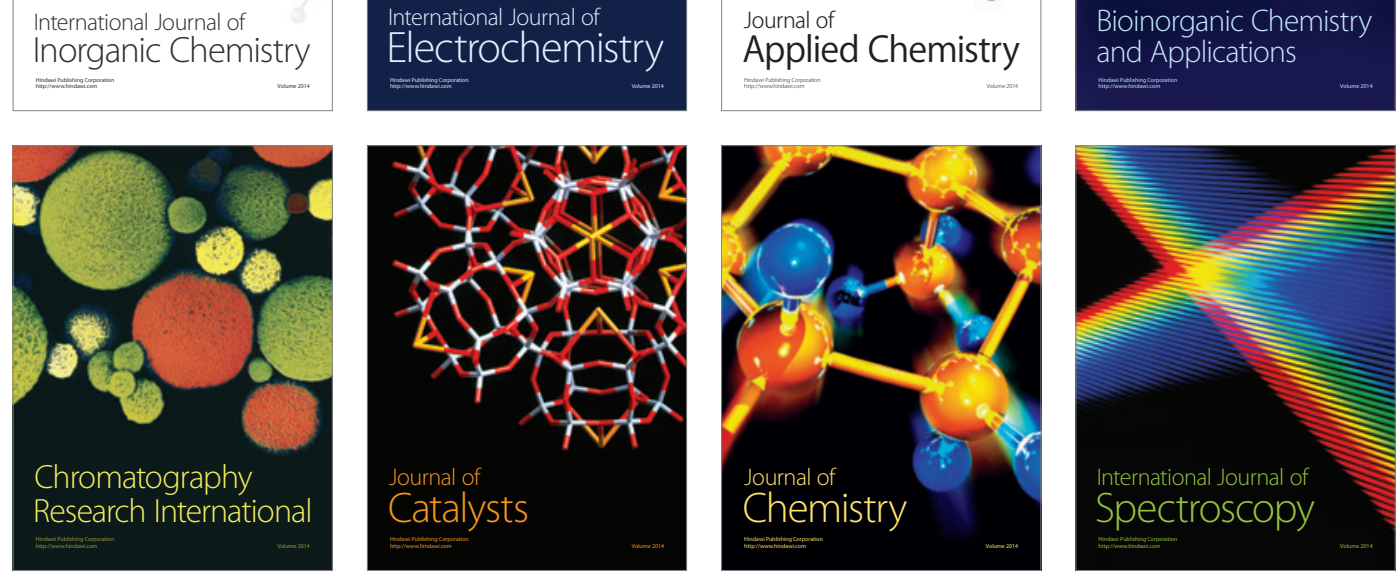